\title{
Gender, Sexual Agency, and Friends with Benefits Relationships
}

\author{
Jasna Jovanovic ${ }^{1} \cdot$ Jean Calterone Williams ${ }^{2}$
}

\begin{abstract}
Recent trends suggest that friends with benefits (FWB) relationships are prevalent among emerging adults on college campuses. Notably, young women are just as likely to participate in these relationships as young men, a finding that differentiates FWBs from heterosexual hook ups, where women traditionally report less participation. As such, it has been suggested that friends with benefits relationships may provide young women an avenue to explore and achieve sexual agency. Yet, whether emerging adults actually perceive friends with benefits relationships as affording women sexual agency has not been explored explicitly. In this study, we focus on female sexual agency and examine whether college women and men perceive FWB relationships as a means of expressing women's sexual agency. Based on focus group discussions with 71 women and 35 men at a large public university, this study explores the myriad ways that students make sense of FWB relationships. Focus group discussions focused on the themes of empowerment, control, and safety in FWB relationships; we examine these themes in order to provide a nuanced analysis of FWB relationships as an increasingly widespread sexual behavior among young people on college campuses.
\end{abstract}

Keywords Gender - Sexual agency · Friends with benefits · Female sexuality $\cdot$ Intimate relationships

Jasna Jovanovic

jjovanov@calpoly.edu

1 Department of Psychology and Child Development, California Polytechnic State University, 1

Grand Ave, San Luis Obispo, CA 93407, USA

2 Department of Political Science, California Polytechnic State University, 1 Grand Ave, San Luis Obispo, CA 93407, USA 


\section{Introduction}

The expression Friends with Benefits (FWB) refers to a form of casual relationship that combines the psychological intimacy of a friendship with the sexual intimacy of a romantic relationship without commitment (Hughes et al. 2005). Recent studies suggest that a majority of college-age men and women report having had at least one FWB relationship (Bisson and Levine 2009; Owen and Fincham 2011; Williams and Jovanovic 2015). The idea that FWB relationships may express heterosexual female sexual agency and liberation is a theme increasingly affirmed by popular media in the United States (Rosin 2012; Taylor 2013). Indeed, young women are just as likely to participate in these relationships as young men, a finding that differentiates FWBs from heterosexual hook ups, where women traditionally report less participation (Bisson and Levine 2009; Furman and Shaffer 2011; Grello et al. 2006; Manning et al. 2005). Yet, whether emerging adults actually perceive FWB relationships as a place where women are empowered has not been directly examined. In this study, we specifically explore whether college women and men perceive FWB relationships as a means of affording women sexual agency.

\section{Friends with Benefits Relationships}

A friends with benefits relationship is distinguished from a hookup because the FWB relationship implies a stronger and more lasting connection between two people. Hook ups are defined as "brief uncommitted sexual encounters among individuals who are not romantic partners or dating each other" (Garcia et al. 2012, p. 161), and may occur between those who are strangers or acquaintances (Paul et al. 2000). FWB relationships, on the other hand, suggest a greater level of intimacy than a hookup. Specifically, the "friendship" aspect of the relationship, the presumption of repeated sexual contact, and an ongoing connection to another person all shape the relationship: "Because these situations represent a greater entanglement of friendship, trust, and emotional comfort, FWBs are distinct from notions of hooking up in some aspects" (Garcia et al. 2012, p. 163). Notably, the formulations of these relationship elements can vary widely (Mongeau et al. 2013), suggesting FWBs are on a continuum of casual sexual relationships (Epstein et al. 2009; Furman and Shaffer 2011).

FWB relationships also differ from hookups in terms of sexual satisfaction. In heterosexual hookups, women are found to be sexually submissive and less likely to report sexual pleasure (Brugman et al. 2010; Currier 2013; Wade 2017). In their quantitative analysis of over 6000 college-age women, Armstrong et al. (2012) found that women were less likely to be sexually satisfied in a hookup than in a more committed relationship. In a follow up qualitative analysis, Armstrong et al. (2012) noted that both men and women reported that men were less concerned with women achieving orgasm in hookups but men were attentive to women's sexual pleasure in more committed relationships. Women's lack of trust in the men who 
approach them, and their expectation that men will be sexually selfish, explains in large part why fewer women than men engage in hookups (Conley 2011).

Unlike hookups, FWB relationships may provide an alternative form of casual intimacy that allows women to express their sexual desires more freely because they experience such relationships as safer given the security provided by the friendship. Bay-Cheng et al. (2009) found that FWB relationships were associated with the highest level of "desire, wanting, and pleasure" compared to all other serious and casual relationship experiences reported by women. They argued that, "FWBs may enable individuals to enjoy the stability, familiarity, and egalitarian balance of platonic friendships as a means of sexual experimentation and gratification" (p. 520). In this context, FWB relationships may represent sexual behavior where young women are able to articulate their sexual needs in a relatively "safe" environment.

Research exploring young women's motivation and satisfaction associated with FWB relationships, however, has resulted in mixed findings. In a sample of 411 emerging adults who completed an on-line survey, Lehmiller et al. (2011) found a common motivation for men to initiate a FWB was sex, while women were more likely to indicate they were motivated by the desire for an emotional connection. Although both the men and the women in their sample were equally committed to both the sexual and friendship aspects of the relationship, more women than men hoped their FWB would develop into a romantic relationship; this is a finding noted in other studies as well (Mongeau et al. 2013; Owen and Fincham 2011). Gusarova et al. (2012) found that although more women than men reported unmet expectations in their FWB, the overall percentage of women who felt this way was low and, in fact, women were equally likely as men to report having had a positive experience in their FWB relationships. Similar positive reports by women have been found in other studies (García et al. 2014; Owen et al. 2013).

Third wave feminist analyses and other examinations of gender and sexuality suggest varied interpretations of heterosexual FWB relationships and their likelihood of providing opportunity to exercise sexual agency (Baumgardner and Richards 2010; Williams and Jovanovic 2015). Yet, the sexual double standard may overshadow the potential for sexual agency, and thus gendered power differentials and tensions would be reflected and play out in FWB relationships. In a previous study, we argued that the relationship between feminist identity, FWB relationships, and sexual agency is complex and multilayered. We noted that although feminist identity did not determine young women's participation in a FWB relationship, those women with a higher feminist identity were less likely to be motivated to engage in these relationships just for sex and reported less overall relationship satisfaction. On the other hand, both the women and men in our sample did not differ in their reported sexual satisfaction. However, our results were correlational so did not allow us to draw conclusions on how sexual agency may be at play (Williams and Jovanovic 2015). 


\section{Female Sexual Agency}

The goal of the present study was to provide extensive information about college students' perceptions of FWB relationships. We were particularly interested in exploring how emerging adults formulate their understandings of gender, sexual agency, and FWB relationships in relation to one another. We used a social construction approach to understand sexuality, arguing that meanings for both gender and sexuality are constructed, or defined, through cultural norms and social institutions (Lorber 1994; Rubin 1984; Vance 1991). As Butler (1990) states, gender and sexuality are best understood as "the effects of institutions, practices, discourses with multiple and diffuse points of origin" (p. ix). Sexuality and gender are categories of identity made real by cultural practices and social institutions, such as family, religion, and education. One dominant social construction of female sexuality that proved particularly relevant in our study relates to the notion that women have less sexual desire than men (Crawford and Popp 2003). Thus, male pleasure is often the focal point of sexual encounters, based on the belief that men "need" sex more frequently and cannot control their desires. Young women hold the responsibility for monitoring and controlling sexual interactions, and may be stigmatized for some sexual activity while men are not. FWBs provide fertile ground for exploring and understanding issues of sexuality; as emerging adults confront this type of relationship, they interpret it within existing social constructions, but also generate new considerations of sexuality and sexual agency.

Researchers have used a variety of definitions for sexual agency, including the recognition of one's sexual desire, the ability to freely express that desire, including sexual self-assertiveness, and healthy sexual behaviors such as initiating condom use (Delgado-Infante and Ofreneo 2014; Fine and McClelland 2007; Fitz and Zucker 2014). Curtin et al. (2011) define sexual agency as sexual self-efficacy, including the belief in one's ability to prevent STIs and unwanted pregnancy, and sexual assertiveness, which relates to the confidence to initiate sex and to communicate one's sexual needs, including refusing sex (see also Fetterolf and Sanchez 2015; Fitz and Zucker 2014). In this study, we operationalize sexual agency through the concepts of empowerment, safety, and control.

Young women struggle to achieve sexual agency for numerous reasons, including sexual pressure and assault, cultural and social constraints that may limit their access to information, and the expectations placed upon them as a result of social constructions of gender and sexuality. For example, though adolescents are surrounded by sexual imagery via the media, they have mixed access to relevant and accurate information about sex, sexual pleasure, and contraception from parents, community agencies, and school-based sexuality education (Brugman et al. 2010). In particular, abstinence-only education, taught in about a third of public high schools that teach sex education, limits instruction about a range of topics including contraception and relies on traditional gender stereotypes, teaching that girls' virginity should be closely guarded and that girls are the "gatekeepers" responsible for regulating sexual encounters (Doan and Williams 2008; Fine and McClelland 2007). Restricted information via sex education is paired with laws and policies 
limiting access to reproductive health care; the combination serves to impede young women's ability to explore and understand their own desires. In this context, sexual agency is not easily achieved.

In addition to institutional barriers to realizing sexual agency, young women face a social context where assertions of sexual liberation clash with the realities of sexual consent. Burkett and Hamilton (2012) analyzed interviews with young women who related numerous instances where they displayed "sexual compliance" rather than sexual agency. Specifically, they were uninterested in having sex, but felt they could not refuse because they had, for example, flirted or gone home with a man. The authors suggest, "The young women we interviewed reflected the contradictory character of postfeminist sensibilities, primarily in the marked discrepancy between their perceptions of women's natural rights to sexual agency and their vilification of their own (and other women's) inabilities to control their everyday sexual encounters with men" (Burkett and Hamilton 2012, p. 817). The clash between expectations and reality meant that they interpreted instances where they had not consented to sex, but nevertheless had a sexual encounter, as their own responsibility. Popular culture, sexual scripts, and even the language of sexual responsibility and safer sex help to produce the conviction that young women are sexually powerful and independent (Moran 2017); when their experiences do not jibe with this conviction, young women may blame themselves for their inability to assert sexual agency (Burkett and Hamilton 2012; Bay-Cheng 2015).

Not surprisingly, gender differences in sexual agency exist; heterosexual men are more likely than heterosexual women to embrace and experience sexual agency. Research indicates that men initiate sex more than women, and that men implicitly associate sex with dominance while women associate it with submission (Fetterolf and Sanchez 2015). In a study completed by Fetterolf and Sanchez (2015) with heterosexual college students, respondents believed that both women and men who displayed sexual agency were less likely to engage in safer sex or to use contraception. Though women who exhibited sexual agency were perceived to be more attractive than those who did not, they were also assumed to have had the highest number of sexual partners, as compared both to men and other women. Women found the perceived traits associated with sexual agency to be negative; they did not want to be considered a "selfish" sexual partner or to be assumed to have had multiple sexual partners. This was not a concern for men, who were more likely to embrace the perceived traits that respondents associated with sexual agency (Fetterolf and Sanchez 2015). Such gender differences express the continued relevance of sexual double standards on college campuses.

A significant amount of research supports the persistence of a double standard (Allison and Risman 2013; Conley et al. 2013; Hamilton and Armstrong 2009; McClelland and Fine 2008; Rudman et al. 2013). Notwithstanding a college culture where a majority of the students experiment with hooking up or friends with benefits relationships, sexual double standards prevail. For example, men may be viewed as sexual agents and women as sexual objects; relatedly, students may rely on the virgin-slut dichotomy to interpret women's sexuality (Crawford and Popp 2003; Delgado-Infante and Ofreneo 2014). Sexually active, heterosexual girls, particularly those in casual sexual relationships or who have multiple sexual partners, risk being 
labeled as "sluts" or even as "pathological" (Conley et al. 2013; Fetterolf and Sanchez 2015; Harad 2003; Kimmel 2012; McClelland and Fine 2008; Tanenbaum 2000; Valenti 2007). Bay-Cheng posits that the double standard has become more complicated than the historic "virgin-slut" dichotomy; now, girls must navigate simultaneously both a "virgin-slut continuum" and an "agency line." Being labeled as a slut does not necessarily translate to presumptions of promiscuity, but rather refers to those who seek "male desire and approval" and are unable to control sexual interactions (Bay-Cheng 2015, p. 282). The threat of being called a slut may serve to undermine young women's ability to seek sexual pleasure, to articulate sexually permissive beliefs, or to openly seek information about their sexuality, thus operating as a form of social control that stunts sexual agency.

\section{Methods}

Given the way that social constructions of sexuality may be multilayered and complex, and the fact that we were interested in understanding the social context for FWB relationships on a college campus, we pursued a qualitative approach using focus groups. The focus groups were designed to capture the myriad ways that students perceive FWB relationships on a college campus, including whether these relationships allow for female sexual agency, specifically in terms of empowerment, control, and safety. As Crawford and Popp (2003) argue,

qualitative studies more readily lend themselves to contextually sensitive phenomena. The questions they can address are more open-ended and diffuse, less abstract and hypothetical.... [F]ocus group discussions are open-ended methods of self-report. In these settings, participants can express beliefs and attitudes in their own terms and provide contextual information to justify or explain their positions (19-20).

Focus groups generate information on collective views and the meaning behind those views (Bloor et al. 2001; Morgan 1997). They allowed us to explore a relatively new phenomenon like FWB relationships by asking open-ended questions that enabled the students, to some extent, to guide the conversation to those issues and dynamics that they identified as most important. To this end, groups were open to both those who had experienced a FWB relationship and those who had not, since they both participate in creating meanings for such relationships on the college campus.

\section{Focus Group Protocol}

We conducted 14 focus groups at a large public university in southern California. Participants were recruited by contacting a number of on-campus student groups as well as through flyers posted across campus and on a number of student Facebook pages. Flyers indicated that participants were required to be a current student at the university and between the ages of 18 and 25 years old. The recruitment materials asked students to share their views on friends with benefits relationships as part of a 
study on college-age students' motivations and satisfaction associated with FWB relationships. Participants had the option of attending one 90-min focus group discussion; groups were configured as either male-only, female-only or co-ed. Interested participants indicated their preferred date and group preference via email. Because group mix can impact the data from focus groups (Stewart and Shamdasani 1990) we allowed participants to self select the group composition where they would feel most able to share their beliefs and experiences and challenge others comfortably. We aimed for the recommended optimum size of 6-8 participants in each group. Once participants indicated their group preference they received a confirmation date, time and location of the selected focus group. Prior to commencing the focus groups, members of our research team were extensively trained on conducting focus groups using a protocol outlined by Krueger and Casey (2000). Two members of our research team then facilitated each focus group. Another research assistant took notes and noted who was speaking in order to later facilitate more accurate transcriptions.

Participants were provided with a consent form that described the purpose of the study and explained that the discussion would be audio recorded. We did not require participants to provide us with any self-identifying information, including demographic data, in order to ensure anonymity. Participants were also provided a non-disclosure form in which they were asked to agree to keep in strict confidence information they heard during the discussion. Any participant who did not consent or agree to the non-disclosure could leave the discussion. No participants selected to leave.

The lead focus group facilitator began the discussion by asking participants to list on paper three characteristics of a FWB relationship. The group shared and discussed their responses. The purpose of this activity was to acknowledge the variety of ways participants might define a FWB, although participant responses showed broad agreement regarding a FWB definition. The facilitator then stated that for the remainder of the discussion, the group would use the following definition of a FWB: "a casual relationship that combines the intimacy of a friendship with the sexual intimacy of a romantic relationship without commitment." This served to ensure that going forward, the participants were all considering the same definition.

The focus group questions addressed a wide-ranging number of issues associated with FWB relationships. These questions were informed by our previous study that involved 138 college-aged participants' responses to an online survey in which questions focused on understanding why young women and men engage in FWB relationships, the degree to which they find such relationships fulfilling, the presence of social stigma or acceptance related to this sexual behavior, and feminist identity (Williams and Jovanovic 2015). The focus group questions reflected our survey but allowed us to explore in greater depth unanswered issues that surfaced from the survey results, particularly participants' perceptions of sexual agency in FWBs. "Appendix" includes our list of the questions used to facilitate our focus groups.

Each focus group session was transcribed verbatim by one transcriber and then checked for accuracy by a second. Each focus group participant was assigned a pseudonym to ensure anonymity. Responses are quoted verbatim in the discussion 
below, and only edited to exclude repeated words and linguistic fillers such as "like" and "um."

\section{Participants}

Recruitment efforts resulted in 6 female-only, 3 male-only and 5 co-ed groups. The total number of participants included 71 women and 35 men. The number of participants in each group ranged from 7 to 11 with the exception of two groups, which had 5 and 6 participants. As noted above, participants were between the ages of 18 and 25 years old.

\section{Data Analysis}

We employed systematic thematic analysis (Braun and Clarke 2012) in order to identify and explore the key themes which surfaced in the focus group discussions. The two principal investigators independently read through transcripts and identified key themes (Hirschman et al. 2006). Four primary themes surfaced across our question prompts, which we use to explore sexual agency. Themes were selected when there was extended conversation in all the groups about the issue. The key themes were: (1) FWB relationships as empowering to young women, (2) FWB relationships as not empowering to young women, (3) FWB relationships as providing a safe option in place of hook-ups, and (4) control and power in FWB relationships.

We created codes for each theme. Coders were trained on our coding rubric, and then two coders were assigned to each transcript. Coders went through the transcript and noted every time an instance of a theme appeared along with the speaker and page number. After coding independently, the coders then met to discuss discrepancies. Discussion occurred until interrater agreement was achieved. A third coder then collated all the instances of each theme across all transcripts.

Beginning with a systematic review of the patterns presented by the themes, we then proposed and explored explanations to make sense of similar events, experiences and feelings described by the students. As the parallels among students' comments became clearer, the concept of sexual agency provided a framework to explore FWB relationships, and enabled us to examine whether and to what degree FWB relationships are a means of expressing or creating sexual agency. Thematic analysis allowed us to group and examine the transcripts' similarities, while simultaneously demonstrating that participants held multiple and multilayered positions and understandings about sexual agency in the context of friends with benefits experiences (Ryan and Bernard 2000). The gender composition of the group did not affect the types of conversations that occurred among the students. Regardless of the gender composition of the group, students were willing to be just as candid, the same themes surfaced, and the themes were discussed in a comparable manner. 


\section{Findings and Analysis}

We organize our results around our four themes. For each, we provide examples of comments that illustrate and explore the theme and analyze the layers of associations with FWB relationships and sexual agency; quotations were selected when they reflected numerous students' remarks. We indicate the gender composition of the group from which the quotation is drawn in parentheses. The students' comments reveal the nuances of empowerment, safety, and control in FWB relationships.

\section{Theme 1: Empowerment}

Given the mixed findings of previous research, it is perhaps not surprising that focus group participants expressed a variety of viewpoints about whether FWB relationships were empowering to young women and men. For those who maintained that they were empowering, students suggested that FWB relationships allow young people to explore their sexuality and enjoy sex. Many used a gendered lens to analyze women's participation, stating that FWB relationships allowed women to be sexual in a culture where men have more license to sexual freedom. FWB relationships were perceived as evidence of a changing culture that gives women more sexual freedom than in the past.

Among those who thought that FWB relationships were empowering, students argued that such "no strings attached" liaisons create opportunities for sexual experimentation. For example, Maddie stated, "I think it's empowering because it kind of lets you experiment with sex without having to have a boyfriend" (co-ed group). Likewise, Jan asserted: "This is a situation where you are allowed to express your sexuality and explore more, like you're encouraged almost and you're not being held back by society's views" (co-ed group).

In bringing a gendered analysis to the question of empowerment, many students argued that FWB relationships were both a reflection of and created opportunities for gender equality. Specifically, by allowing women to explore their sexuality and get their sexual needs met in a way that is similar to men's ability to do so, FWB relationships call into question the sexual double standard and demonstrate that women have sexual desires similar to men's. Scott declared, "I think culturally we tend to view women as not these very sexual creatures. And so to think 'oh a girl just wanting sex or something like that, wanting to be in a friends with benefits,' that's kinda weird. But I think it's pretty much the same intent for everyone and we just fail to acknowledge that...everyone has urges and drives" (male-only group). Similarly, Matt maintained, "It's a little antiquated way of looking at it thinking that girls have to suppress their desires, or the idea that they do, because I don't think that they do. They can freely do whatever the hell they want because they're between 18 and 22 and they're in their prime of their experimenting years" (maleonly group). Agatha's comments repeat these themes as well:

I think it's empowering from the wider picture of women's roles in the past, where it wasn't as socially appropriate for women to initiate sex or pursue sex 
without commitment. I think from that angle we're in a very different time than a few decades ago, where women can freely live the sexual life that they want and be supported by that. It's awesome that it doesn't even cross people's minds because that says a lot (co-ed group).

The students in our study echoed many of the arguments that are essential to third wave feminist theory. Young women's sexual desires are championed and normalized in third wave feminism, which heralds women's sexual autonomy and independence, insisting that "women have a sexuality and can be as lustful as men" (Baumgardner and Richards 2010, p. 166). One of the key elements in third wave is the ability to reject cultural proscriptions about sexuality, particularly for women: "Feminism tells you it's okay to make decisions about your sexuality for yourself. Because when it comes down to it, what's more powerful and important than being able to do what you want with your body without fear of being shamed or punished?" (Valenti 2007, p. 30). In the focus group discussions, Terry articulated the same idea in terms of FWB relationships: "Choosing what you want to do with your sexuality and with your body is the empowering part of it" (female-only group).

\section{Theme 2: Lack of Empowerment}

Although students discussed empowering aspects of FWB relationships, many viewed them as fraught with tensions and not liberating for women. In particular, based on social constructions of gender, there were multiple social stigmas for young women related to casual sexual behavior. Men, on the other hand, were not stigmatized but often applauded for engaging in FWB relationships.

In exploring the impact of social constructions of gender on FWB relationships, students referred to the notion that women are viewed as gatekeepers in heterosexual sexual activity. It is women who must decide whether and to what extent sexual activity will be allowed, while it is assumed that men will not feel conflicted about sexual activity. Beth articulates the notion that women are invested in controlling sexual encounters:

When a guy has casual sex, he's not feeling personal issues with having sex with someone - a stranger or an acquaintance. But when it's a girl, you think about giving away your flower-not virginity but you know what I meanactually having sex with the guy is a bigger deal [for the girl] than the guy.... I think that personal battle between women and men makes it hard for the woman to feel confident in her decision to have sex with someone. As opposed to a guy who probably doesn't really think twice about it (female-only group).

In a different focus group Nathan described a similar dynamic:

I think girls or women aren't naturally-well I'm sure we are all naturally horny in some sense or form- but there's this social stigma, whether it be about religion or culture or whatever it may be, somehow globally women need to preserve themselves or need to hold higher standards than men. That is instilled as a young lady, so they may feel guilty or they may feel reluctant to 
engage in those kind of actions because of the way they were raised or the way their culture is (male-only group).

Both students' comments reflect social constructions of gender that define men as "naturally" interested in sex and willing to engage in sexual encounters whenever the opportunity presents itself, while women are perceived to be less sexually motivated and invested in limiting their sexual partners (Kimmel 2012).

Even in the context of widespread sexual experimentation in college, the pressure on young women to maintain some level of sexual "purity" plays out in the ways that college students participate in and analyze FWB relationships. For example, Mary states, "I know girls who are just like 'oh, I can't [participate in FWB relationships]. Once I let down that wall of saying oh I'm going to be open to this,' they're worried about how many people they're actually going to end up with and how that's going to affect their future relationships" (female-only group). The assertion that heterosexual women will ruin their chances to find mates or to successfully marry if they engage in premarital sex, especially casual sex, has been revived and somewhat mainstreamed through abstinence-only sex education. In contrast to the loosening of sexual mores, the conservative Christian movement has promoted the view that young women's sexuality must be protected (Doan and Williams 2008).

Students explained that the gender constructions associated with interpreting and judging FWB relationships often result in the application of sexual double standards. They referred repeatedly to a sexual double standard whereby women and men are judged differently by others for casual sexual behavior. Indeed, it is striking how a majority of students repeated the same points as the students quoted in this section; over and over, students intoned that a double standard exists, and that men are congratulated for casual sexual activity while women are scorned.

For example, Jan asserted,

I think men are viewed as more masculine, like okay cool they're getting what they want... [But] they're like, "that girl is kind of slutty, she is not committing herself yet, she is giving her body away." And that's just what society has engrained in our brains. Men are expected to do this, but women aren't expected to embrace their sexuality. Because they are embracing their sexuality, they are labeled a slut [and] looked down upon (co-ed group).

In another focus group, Penny made a similar point:

When you think of a guy hooking up or having multiple sexual relationships or having very casual relationships, we don't think anything. We don't think twice about it. It's like "oh, he's a guy; it's what guys do." But when you hear about a girl doing that, you tend to think, "oh she's slutty." There's more of a stigma against women expressing sexual freedom than men in our culture (female-only group).

Not only do men escape being stigmatized for engaging in FWB relationships, they may receive positive encouragement for sexual experimentation. Scott's comments are repeated numerous times by students in the focus groups: "For men, it's kind of 
like, 'Yeah, way to go, you've got a friends with benefits!' With women it could be like, 'Oh, that slut, ugh!'” (male-only group).

These students suggest that the sexual double standard is based upon cultural expectations that men are "naturally" sexual and rightly may pursue sexual gratification, the idea that "it's what guys do." On the other hand, women are expected to wish for and seek committed relationships, and to keep their sexual desires controlled and even concealed. FWB relationships undermine these cultural expectations by providing an opportunity for heterosexual women to engage in one form of casual sex, and by revealing the degree to which they have sexual desires on par with men's. For pursuing these desires, however, women are socially punished by being labeled as promiscuous and even unnatural for "not committing" to a romantic relationship.

Many students also pointed out that "slut shaming" of women occurs even though FWB relationships have become the cultural norm on some college campuses. Derek suggests that even within a general sense of acceptance for casual sexual behavior, women still get stigmatized for participating: "I think it's fairly accepted. However, that being said... it has a negative stigma, especially if you're a woman. If you have a lot of FWB relationships, and you're a woman-like whore, slut, that all gets thrown around" (male-only group). On the other hand, Nick suggests that FWB relationships are the norm for men exclusively, and that men may even feel pressure to engage in casual sexual behavior to meet the expectations associated with social constructions of masculinity: "I think for guys sometimes, there can be like a social pressure behind it. They feel like going into this college life, they need to have that kind of relationship because that's the social norm" (male-only group). Our research found extensive support for the existence of a double standard. Even in a context where casual sexual activity is relatively widespread, a robust sexual double standard is present.

\section{Theme 3: Safety}

A number of our questions evoked discussions around the theme of FWB relationships as a "safe zone" for women to enjoy sex. Specifically, many women across the focus groups described how one motivation for engaging in a FWB was a sense of comfort in having sex with a person familiar to them. Agatha said, "I mean, for me personally, so much of it has to do with comfort. Like I'm not comfortable hooking up with someone I don't know. So that automatically puts the people I'd be willing to hook up with as my friends, you know or at least acquaintances" (co-ed group). Penny noted, "The nice thing about a friends with benefits, is it's a really safe way to just have sex. You know the person, personally. You know their background, history, and if that's what you want to do-you just want to have sex-that's probably like the safest, most secure way to go about it on a regular basis" (female-only group).

Recent national statistics indicate that there has been a dramatic increase in the number of reported sexual assaults on college campuses; specifically from 2001 to 2013 the number of reported forcible sex crimes increased 126\% (Zhang et al. 2016). Young women, aware of their risk of sexual assault, may perceive FWB 
relationships as allowing them to better know the males with whom they are hooking up. As Jennifer expressed, "I think I'd rather have a friends with benefits with someone than just hook up with a random guy because... what if I tell him to stop and he doesn't stop" (female- only group).

Relatedly, safety meant to these students that they were less at risk for STIs or pregnancy because they were having sex with a partner they knew and trusted. Yet, for some there was also an admission of being lulled into a sense of safety that in fact could put partners more at risk. As one female participant said, "We never use a condom, for some reason. I'm not saying that's a good thing. Versus one night stands or a hook-up, [when] there's more incentive [to use a condom]" (co-ed group). Most of the women and men across the groups, however, described FWB relationships as not monogamous and therefore emphasized the use of birth control in these relationships. Mary said, "I think it's something you use definitely, it's like wear a condom or it's not happening, sorry" (female-only group). Ryan stated, "I feel much more comfortable if the girl's on the pill and I'm using condoms" (co-ed group).

Another aspect to the theme of safety that was highlighted across our discussions was emotional safety. Many of our participants described FWB relationships to be less emotionally risky than other relationships. "It's kind of this evolved safe zone, where you can be sexually active without subjecting yourself to emotional hurt" (Dolly, co-ed group). Males also expressed this sentiment. As one male participant in one of our co-ed groups stated, "I feel like it's a way to kind of avoid getting hurt" (co-ed group). Yet there was the recognition that emotional hurt was only avoided if both partners in an FWB could keep "emotions in check." As Derek, a participant in one of our male-only groups noted, "I think at some point, if it carries on too long, [someone] is gonna start to develop feelings, it's just kinda human nature."

As we noted, it has been reported in previous studies on FWB relationships that women are more likely to hope for a change in their relationships, while men are more likely to wish for it to remain the same (Grello et al. 2006; Owen and Fincham 2011). Our participants did not confirm this. As one of our male participants stated, "I think guys and girls have the same amount of emotions. I think guys would like to think that they have more emotional control, but they don't" (co-ed group). Although our participants did not agree on whether women were in fact more emotionally invested in FWB relationships, there appeared to be consensus that this continues to be the common stereotype. A female student noted, "Women always want relationships. Not really but that's what people say" (co-ed group). As Amber explained, "I feel like among my friends there is sort of an assumption that a girl always wants something more. I know that I've had to convince guys that 'no I actually don't want anything else" (female-only group). It appears again that young women are caught between the perceptions shaped by a double standard and their own desires. 


\section{Theme 4: Control}

When exploring themes of empowerment, many students interpreted it as having less to do with sexual freedom and more to do with who initiates sexual activity, sets boundaries in the relationship, and the like. Savannah pointed out,

Something else that also comes into play is who's asking... "oh let's go hook up." Is the boy texting her or is the girl texting him? Depending on what happens in those situations, if the girl is asking, "hey, come over let's hook up," then it's empowering because she has the control to ask and the ability to ask. Whereas if he's asking for it, she wants to please him and say "sure! I'll be right over" (female-only group).

Although she was in a different focus group, Agatha's comments correspond to Savannah's: "I think any guy participating in an FWB relationship is aware of the fact that the other person can essentially pull out at any time; they're not bound in any way. That's probably humbling for men because women have equal power in their involvement" (co-ed group). As Nick says when discussing empowerment, "it has less to do with gender and more to do with who's calling the shots and cares less" (male-only group).

It is unclear, based on the participants' discussions, why FWB relationships would be perceived as allowing women more control than a conventional romantic relationship. Perhaps it is the transitory and loose nature of such liaisons, and their cultural newness, that allow young women to feel that they can take control more readily than in a romantic relationship. Given the scripts that have long been associated with romantic relationships, where men ask women out and take the lead, young women may perceive FWB relationships to be less structured by gender norms and expectations. As Erynn describes, "When I have more control in the friends with benefits, I am more empowered because I know that... I can pretty much dictate how it's going to go" (female-only group). But Erynn goes on to qualify this control when she says, "Whoever's less attached has more control." A number of students tempered their enthusiasm for FWB relationships' potential for empowerment in their discussions of control. Many young women echoed Madeline's sentiments that FWB relationships could undermine empowerment:

I think for women it depends on if they're taking control of the situation or not, and if they're fulfilling their needs. It's like one girl might just want to have sex, and so I think it's empowering if she's getting what she wants, and doing it in a safe way. But if she has emotional needs in the situation, and he only wants it for sex, then maybe it's not very empowering, because she's not getting what she wants (female-only group).

Thus, differing expectations for the relationship and levels of commitment can mean FWB relationships have a number of drawbacks. Amber describes that among her friends, when a woman is in a FWB for "very long," the suspicion is always she is too emotionally invested and the judgment among her peers is "why does she keep doing this to herself?" (female-only group). 


\section{Discussion}

The focus group discussions made clear that there are diverging views of sexuality, gender constructions, and casual sexual behavior that compete for dominance on today's college campuses. We found that college students had mixed assessments of friends with benefits relationships. While some identified FWBs as empowering by enabling women to explore their sexuality in a relatively safe environment, others cited the impact of sexual double standards in limiting women's engagement with and enjoyment of such relationships.

Previous research has suggested that women who had a FWB relationship engaged in as much sexual behavior with their partners as men did (Furman and Shaffer 2011) and report similar levels of sexual satisfaction (Williams and Jovanovic 2015). In some of the literature on casual sex, FWB relationships are included in the broader definition of a hookup, and these studies find similar references to sexual freedom. Aubrey and Smith (2013), for example, find that college students perceive hooking up (including FWB relationships) as a way to feel "sexually powerful and in control" and to express sexual freedom: "Women report a feeling of empowerment from hooking up just as much as men do" (Aubrey and Smith 2013, p. 438; Hamilton and Armstrong 2009; Stepp 2007). Other research on hookups, however, suggests that women are more sexually satisfied in committed relationships as opposed to more casual sexual encounters, as measured by orgasms (Armstrong et al. 2012). Perhaps this is explained by the attitudes of both women and men toward women's sexual satisfaction in hookups; that is, women are entitled to sexual pleasure in a relationship but not in a hookup (Armstrong et al. 2012).

While some students in our study stated that FWB relationships allow for sexual experimentation and thus call into question traditional beliefs that women are less sexual than men, others noted that women are stigmatized for participating in FWB relationships precisely because of the cultural view that women's sexual desires are not "naturally" on par with men's (Baumgardner and Richards 2010; Kimmel 2012; Valenti 2007). A wholesale proscription against women's participation in FWB relationships was not apparent, however, as many students noted that casual sexual alliances have become a norm on campus. Nonetheless, women walk a thin line between acceptable participation in FWB relationships and being "slut shamed" (Armstrong et al. 2014; Carr 2013; Conley et al. 2013; Harad 2003; McClelland and Fine 2008; Valenti 2007). As a result, FWB relationships sometimes are perceived as empowering and in other cases as disempowering for young women.

Women, moreover, may attempt to avoid being labeled as a slut by behaving according to the stereotypes that they should covet and aspire to a conventional romantic relationship and not casual sex. Their behavior within FWB relationships is shaped by the social constructions of gender and sexuality and by the related sexual double standard. Although some of the academic literature on double standards tries to distinguish between perception and behavior in double standards (Marks and Fraley 2005), we found little distinction. Perceptions of double standards clearly shaped behavior. In particular, in the focus group discussions, women stated that they weighed sexual double standards in deciding whether to take 
part in FWB relationships. In this sense, awareness of or concerns about possible reproach from other students impacted young women's sexual choices and behavior.

In the focus group discussions, students also distinguished between FWB relationships and hook ups, particularly by noting that they viewed FWB relationships as "safer" than other forms of casual sexual behavior. Given that they knew their partners, sometimes very well, it appears that the "friend" aspect of FWB relationships led young women to trust that they were more secure from sexual assault and STIs than in a more casual hook up. Despite women's belief that they are safer with a friend, however, statistics on sexual assault might suggest otherwise. Since sexual assault on college campuses is more likely to occur with an acquaintance or friend, FWB relationships may be no safer than hook ups. Specifically, $85-90 \%$ of sexual assaults reported by women on college campuses are perpetrated by someone that the victim knows (National Institute of Justice 2016). Thus, at least in the context of sexual assault, FWB relationships may provide a false sense of security for young women. It will be important for future investigations to determine whether there is a higher or lower probability of sexual assault in FWB relationships.

Both the women and men in our study described FWB relationships as a context where either gender can determine if the relationship will occur and when it will end. This more equal ability to "call the shots" deviates from traditional romantic relationships and even other forms of casual relationships like hook ups where males are most often in control (England et al. 2012; Wade 2017). In this way, FWB relationships provided young women a certain sense of empowerment. Yet, this was only true if women were as likely as men to exercise this control and were not more often the ones to become emotionally invested. Our results suggested that the control in FWB relationships is in fact equitable. However, given the previous findings by others suggesting that women more often than men hope that their FWB will move into a committed romantic relationship, the notion of control should continue to be explored in future research.

In sum, our results suggest that women want to live in a social context where they are truly in control of their sexuality. But it is difficult to escape the stigmas related to the social constructions of gender and sexuality that inhibit their ability to express their sexual desires and to explore their sexual identities. Thus, the sexual autonomy so central to sexual agency remains a goal rather than a reality for most young women. A number of young people in this study viewed friends with benefits relationships as a promising venue for women to sexually experiment and to practice sexual agency. At present, however, most students believed that the social context for FWB relationships did not differ much from the gendered assumptions governing other heterosexual forms of intimacy and relationships. To truly understand the dynamics within FWB relationships, and the ways in which women feel a sense of agency, it will be important that future investigations study the perspectives of both partners in the relationship. 


\section{Limitations}

In addition to those discussed in this paper, we conducted four focus groups that were advertised as queer-identified groups. Two female-only and two male-only focus groups were convened for a total of 12 queer-identified participants. Given this very small sample, we omitted these participants from our analysis because we did not feel we could accurately draw conclusions about queer-identified FWB experiences. To date, there are no existing studies that specifically examine FWB experiences of non-heterosexual young adults. Research focused specifically on hook-ups suggest there may be differences in sexual and emotional satisfaction when comparing heterosexual and queer men and women (Mark et al. 2015). Other research suggests that hookup culture can serve as an opportunity structure where sexual identities are explored (Rupp et al. 2014). Therefore, the meaning of sexual agency explored in our analysis likely is complicated by the experiences and perspectives of lesbian, gay, and bisexual students. Though we scheduled queeridentified groups, LGBTQ students could have attended one of the other focus groups; however, no students identified themselves as LGBTQ or discussed samesex relationships in the non-queer-identified focus groups.

Moreover, because we did not have our participants formally identify their race/ ethnicity, class, or sexual orientation, we cannot generalize that our findings represent emerging adult perceptions broadly. To date there is little research that specifically considers race/ethnicity, class, or sexual orientation in FWB relationships. In one of the few studies that focused on race/ethnicity, Williams and Adams (2013) found similar likelihood of participation in FWBs among Mexican-American and Anglo youth, though Mexican-American women were more likely to hope for a committed relationship, creating more unmet expectations. Study participants were high school students rather than in college, however, which may have impacted the findings.

Research on the college hookup culture is more intersectional. For example, some studies demonstrate that non-white college students are less likely to participate in these relationships, not for lack of desire but because of lack of opportunities resulting from racial preferences among potential partners that favor whites (Kuperberg and Padgett 2016; Spell 2016). Other research suggests that more privileged college women are more at ease with hooking up than lower income college women (Hamilton and Armstrong 2009; Uecker et al. 2015). And still others find few differences based on race or class (Fielder et al. 2013).

Because students self-selected to participate in our focus groups, some voices and opinions may not appear in the discussions. For example, students with strong religious convictions are less likely to participate in casual sexual activity (Ahrold and Meston 2010), so they may have been reticent to join one of our focus groups. In the same vein, because the student culture and dominant mores found at a California school may be distinctive, it is unclear whether the findings represent students nationwide.

Despite these limitations, focus groups seem to be a promising approach to better understand friends with benefits relationships or other aspects of sexuality. By allowing over 100 students to explore sexual agency and FWB relationships 
collectively, we were able to delve deeply into their views and understand the nuances of this relatively new form of relationship. Our results emphasize the value of listening to students' voices as they are trying to make sense of a culture of casual sex. Notions of safety and control were dominant themes in students' explorations of sexual agency, cementing the importance of continuing to distinguish FWBs from hook ups in further research.

Acknowledgements This research was supported in part by funding from the authors' institution. The views expressed herein do not necessarily reflect those of the sponsor. We would like to express our sincere thanks to the many undergraduate and graduate students who provided assistance over the course of this project: Emily Aguilar, Jerusha Beebe, Anna Black-Hogins, Mick Bruckner, Megan Carnow, Alex Fernandez, Ilea Harrington, Natalie Hendricks, Markie Jorgensen, Nikki Lanshaw, Melina Manetti, Marguerite McHale, Natalie Neach, Luke Politi, LaurynPreeshl, Hamzah Ramadan, Xavier Ramos, Travis Raynaud, Michelle Tan, Sydney Tanimoto, Taelor Trimble, Sevelyn Van Ronk.

\section{Compliance with Ethical Standards}

Conflict of interest The authors declare that they have no conflict of interest.

Ethical Approval All procedures performed in studies involving human participants were in accordance with the ethical standards of the institution and with the 1964 Helsinki declaration and its later amendments or comparable ethical standards. This article does not contain any studies with animals performed by any of the authors.

Informed Consent Informed consent was obtained from all individual participants included in the study.

\section{Appendix: Focus Group Questions}

1. We want you to think about someone you know who has considered having a FWB relationship — or if you have had one, you can also think of your own relationship.

(a) why did-or why didn't - the person decide to participate in a FWB relationship?

(b) for those that did-was the experience mostly positive or mostly negative or somewhere in the middle? Why?

2. Do you think the reasons men and women have FWB relationships are similar or different?

3. Is there any negotiation or discussion that takes place between two people who are considering a FWB relationship?

4. Would you say that the degree of communication between a hook up, FWB, and relationship are similar or different?

5. If you start communicating with each other about the relationship or your expectations, is it still a FWB relationship, or does communication make it into something else? 
6. What are your thoughts on using a FWB relationship as a transition into a romantic relationship?

7. Is alcohol a motivating factor in whether students have a FWB?

8. How do you think people who participate in FWB relationships are viewed by people who know about it?

9. Do you think there are differences in the way women and men who participate in FWB relationships are viewed by people who know about it?

10. Are men and women in FWB relationships treated the same way by people who know about it?

11. Is there shared power or control in FWB relationships? What would be indicators of who has more power or control?

12. Do you think engaging in a FWB relationship is empowering or not empowering for young women? for young men?

13. Is a FWB relationship more, less, or equally empowering as a hookup for young women? for young men?

14. In another focus group, some students said that generally, women aren't encouraged to be sexual beings or to freely experiment sexually, but that men are. They said that FWB relationships can be empowering for women because it gives them a chance to experiment and be sexual beings. What do you think about that?

15. Do you think that FWB relationships are an arena in which women and men are pretty equal or pretty unequal?

16. Are men or women more sexually satisfied in a FWB, or are both equally satisfied?

17. Would you say that women OR men have the power to decide what will happen in the FWB relationship? (e.g. who's doing the calling, how often they see each other, monogamous or not, who's making the rules, if they tell other people)

18. If you could define FWB relationships as feminist, unfeminist, or somewhere in the middle, how would you define them? Why?

19. Follow up: How are you defining "feminism"? What does it mean to you? Do you think other people your age define it the same way?

20. Are students likely to use condoms or other forms of contraception in a FWB relationship? Why or why not?

21. Is there anything we haven't talked about that you think is important?

\section{References}

Ahrold, T., \& Meston, C. (2010). Ethnic differences in sexual attitudes of U.S. college students: Gender, acculturation, and religiosity factors. Archives of Sexual Behavior, 39, 190-202.

Allison, R., \& Risman, B. J. (2013). A double standard for "Hooking Up:" How far have we come toward gender equality? Social Science Research, 42, 1191-1206.

Armstrong, E. A., England, P., \& Fogarty, A. K. (2012). Accounting for women's orgasm and sexual enjoyment in college hookups and relationships. American Sociological Review, 77, 435-462. 
Armstrong, E. A., Hamilton, L. T., Armstrong, E. M., \& Seeley, J. L. (2014). "Good Girls": Gender, social class, and slut discourse on campus. Social Psychology Quarterly, 77, 100-122.

Aubrey, J. S., \& Smith, S. E. (2013). Development and validation of the endorsement of the Hookup Culture Index. Journal of Sex Research, 50, 435-448.

Baumgardner, J., \& Richards, A. (2010). Manifesta: Young women, feminism, and the future. New York: Farrar, Straus and Giroux.

Bay-Cheng, L. (2015). The agency line: A neoliberal metric for appraising young women's sexuality. Sex Roles, 73, 279-291.

Bay-Cheng, L. Y., Robinson, A. D., \& Zucker, A. N. (2009). Behavioral and relational contexts of adolescent desire, wanting, and pleasure: Undergraduate women's retrospective accounts. Journal of Sex Research, 46, 511-524.

Bisson, M. A., \& Levine, T. R. (2009). Negotiating a friends with benefits relationship. Archives of Sexual Behavior, 38, 66-73.

Bloor, M., Frankland, J., Thomas, M., \& Robson, K. (2001). Focus groups in social research. London: Sage.

Braun, V., \& Clarke, V. (2012). Thematic analysis. In H. Cooper (Ed.), APA handbook of research methods in psychology (Vol. 2, pp. 57-71). Washington, DC: American Psychological Association.

Brugman, M., Caron, S. L., \& Rademakers, J. (2010). Emerging adolescent sexuality: A comparison of American and Dutch college women's experiences. International Journal of Sexual Health, 22, $32-46$.

Burkett, M., \& Hamilton, K. (2012). Postfeminist sexual agency: Young women's negotiations of sexual consent. Sexualities, 15, 815-833.

Butler, J. (1990). Gender trouble: Feminism and the subversion of identity. New York: Routledge.

Carr, J. (2013). The SlutWalk movement: A study in transnational feminist activism. Journal of Feminist Scholarship, 4, 24-38.

Conley, T. (2011). Perceived proposer personality characteristics and gender differences in acceptance of casual sex offers. Journal of Personality and Social Psychology, 100, 309-329.

Conley, T. D., Ziegler, A., \& Moors, A. C. (2013). Backlash from the bedroom: Stigma mediates gender differences in acceptance of casual sex offers. Psychology of Women Quarterly, 37, 392-407.

Crawford, M., \& Popp, D. (2003). Sexual double standards: A review and methodological critique of two decades of research. The Journal of Sex Research, 40, 13-26.

Currier, D. (2013). Protecting emphasized femininity and hegemonic masculinity in the hookup culture. Gender \& Society, 27, 704-707.

Curtin, N., Ward, M., Merriwether, A., \& Caruthers, A. (2011). Femininity ideology and sexual health in young women: A focus on sexual knowledge, embodiment, and agency. International Journal of Sexual Health, 23, 48-62.

Delgado-Infante, M. L., \& Ofreneo, M. A. P. (2014). Maintaining a "good girl” position: Young Filipina women constructing sexual agency in first sex within Catholicism. Feminism \& Psychology, 24, 390-407.

Doan, A. E., \& Williams, J. C. (2008). The politics of virginity: Abstinence in sex education. Westport, CT: Praeger.

England, P., Shafer, E. F., \& Fogarty, A. C. K. (2012). Hooking up and forming romantic relationships on today's college campuses. In M. Kimmel \& A. Aronson (Eds.), The gendered society reader (5th ed., pp. 559-572). New York: Oxford University Press.

Epstein, M., Calzo, J. P., Smiler, A. P., \& Ward, L. M. (2009). "Anything from making out to having sex": Men's negotiations of hooking up and friends with benefits scripts. Journal of Sex Research, 46, 414-424.

Fetterolf, J., \& Sanchez, D. (2015). The costs and benefits of perceived sexual agency for men and women. Archives of Sexual Behavior, 44, 961-970.

Fielder, R., Walsh, J., Carey, K., \& Carey, M. (2013). Predictors of sexual hookups: A theory-based, prospective study of first-year college women. Archives of Sexual Behavior, 42, 1425-1441.

Fine, M., \& McClelland, S. I. (2007). The politics of teen women's sexuality: Public policy and the adolescent female body. Emory Law Journal, 56, 993-1038.

Fitz, C. C., \& Zucker, A. N. (2014). Feminist with benefits: College women's feminist beliefs buffer sexual well-being amid hostile (not benevolent) sexism. Psychology of Women Quarterly, 38, 7-19.

Furman, W., \& Shaffer, L. (2011). Romantic partners, friends, friends with benefits, and casual acquaintances as sexual partners. Journal of Sex Research, 48, 554-564. 
Garcia, J. R., Reiber, C., Massey, S. G., \& Merriwether, A. M. (2012). Sexual hookup culture: A review. Review of General Psychology, 16, 161-176.

García, H., Soriano, E., \& Arriaza, G. (2014). Friends with benefits and psychological wellbeing. Procedia-Social and Behavioral Sciences, 132, 241-247.

Grello, C. M., Welsh, D. P., \& Harper, M. S. (2006). No strings attached: The nature of casual sex in college students. Journal of Sex Research, 43, 255-267.

Gusarova, I., Fraser, V., \& Alderson, K. G. (2012). A quantitative study of "friends with benefits" relationships. The Canadian Journal of Human Sexuality, 21, 41-59.

Hamilton, L., \& Armstrong, E. A. (2009). Gendered sexuality in young adulthood double binds and flawed options. Gender \& Society, 23, 589-616.

Harad, A. (2003). Reviving Lolita; or, because junior high is still Hell. In R. Dicker \& A. Piepmeier (Eds.), Catching a wave: Reclaiming feminism for the 21st century (pp. 81-98). Boston, MA: Northeastern University Press.

Hirschman, C., Impett, E., \& Schooler, D. (2006). Dis/embodied voices: What late-adolescent girls can teach us about objectification and sexuality. Sexuality Research \& Social Policy, 3, 8-20.

Hughes, M., Morrison, K., \& Asada, K. J. K. (2005). What's love got to do with it? Exploring the impact of maintenance rules, love attitudes, and network support on friends with benefits relationships. Western Journal of Communication, 69, 49-66.

Kimmel, M. S. (2012). The gendered society (5th ed.). New York: Oxford University Press.

Krueger, R. A., \& Casey, M. A. (2000). Focus groups: A practical guide for applied research. Thousand Oaks, CA: Sage.

Kuperberg, A., \& Padgett, J. E. (2016). The role of culture in explaining college students' selection into hookups, dates, and long-term romantic relationships. Journal of Social and Personal Relationships, 33, 1070-1096.

Lehmiller, J., VanderDrift, L., \& Kelly, J. (2011). Sex differences in approaching friends with benefits relationships. Journal of Sex Research, 48, 275-284.

Lorber, J. (1994). Paradoxes of gender. New Haven: Yale University Press.

Manning, W. D., Longmore, M. A., \& Giordano, P. C. (2005). Adolescents' involvement in non-romantic sexual activity. Social Science Research, 34, 384-407.

Mark, K. P., Garcia, J. R., \& Fisher, H. E. (2015). Perceived emotional and sexual satisfaction across sexual relationship contexts: Gender and sexual orientation differences and similarities. Canadian Journal of Human Sexuality, 24, 120-130.

Marks, M. J., \& Fraley, R. C. (2005). The sexual double standard: Fact or fiction? Sex Roles, 52, 175-186.

McClelland, S. I., \& Fine, M. (2008). Rescuing a theory of adolescent sexual excess: Young women and wanting. In A. Harris (Ed.), Next wave cultures: Feminism, subcultures, activism (pp. 83-102). New York: Routledge.

Mongeau, P. A., Knight, K., Williams, J., Eden, J., \& Shaw, C. (2013). Identifying and explicating variation among friends with benefits relationships. Journal of Sex Research, 50, 37-47.

Moran, C. (2017). Re-positioning female heterosexuality within postfeminist and neoliberal culture. Sexualities, 20, 121-139.

Morgan, D. L. (1997). Focus groups as qualitative research. London: Sage.

National Institute of Justice. (2016). Sexual assault on campus. http://www.nij.gov/topics/crime/rapesexualviolence/campus/Pages/welcome.aspx.

Owen, J., \& Fincham, F. D. (2011). Effects of gender and psychosocial factors on "friends with benefits" relationships among young adults. Archives of Sexual Behavior, 40, 311-320.

Owen, J., Fincham, F. D., \& Manthos, M. (2013). Friendship after a friends with benefits relationship: Deception, psychological functioning, and social connectedness. Archives of Sexual Behavior, 42, 1443-1449.

Paul, E. L., McManus, B., \& Hayes, A. (2000). "Hookups": Characteristics and correlates of college students spontaneous and anonymous sexual experiences. The Journal of Sex Research, 37, 76-88.

Rosin, H. (2012). The end of men: And the rise of women. New York: Riverhead.

Rubin, G. (1984). Thinking sex: Notes for a radical theory of the politics of sexuality. In C. Vance (Ed.), Pleasure and danger (pp. 267-319). New York: Routledge.

Rudman, L. A., Fetterolf, J. C., \& Sanchez, D. T. (2013). What motivates the sexual double standard? More support for male versus female control theory. Personality and Social Psychology Bulletin, 39, 250-263.

Rupp, L. J., Taylor, V., Regev-Messalem, S., Fogarty, A. C. K., \& England, P. (2014). Queer women in the hookup scene: Beyond the closet? Gender and Society, 28, 212-235. 
Ryan, G. W., \& Bernard, H. R. (2000). Data management and analysis methods. In N. K. Denzin \& Y. S. Lincoln (Eds.), Handbook of qualitative research (pp. 769-802). Thousand Oaks, CA: Sage.

Spell, S. A. (2016). Race relations and racial inequality in hookup culture. Dissertation Abstracts International, 77, 10-A.

Stepp, L. S. (2007). Unhooked: How young women pursue sex, delay love and lose at both. New York, NY: Penguin.

Stewart, D. W., \& Shamdasani, P. M. (1990). Focus groups. Theory and practice. London: Sage.

Tanenbaum, L. (2000). Slut! Growing up female with a bad reputation. New York, NY: Harper Perennial. Taylor, K. (2013, July 14). Sex on campus: She can play that game, too. The New York Times (p. ST1).

Uecker, J., Pearce, L., \& Andercheck, B. (2015). The four U's: Latent classes of hookup motivations among college students. Social Currents, 2, 163-181.

Valenti, J. (2007). Full frontal feminism: A young woman's guide to why feminism matters (1st ed.). Berkeley, CA: Seal Press.

Vance, C. S. (1991). Anthropology rediscovers sexuality: A theoretical comment. Social Science and Medicine, 33, 875-884.

Wade, L. (2017). American hookup: The new culture of sex on campus. New York: W.W. Norton \& Co.

Williams, L., \& Adams, H. (2013). Friends with benefits or "friends" with deficits? The meaning and contexts of uncommitted sexual relationships among Mexican American and European American adolescents. Children and Youth Services Review, 35, 110-117.

Williams, J. C., \& Jovanovic, J. (2015). Third wave feminism and emerging adult sexuality: Friends with benefits relationships. Sexuality and Culture, 19, 157-171.

Zhang, A., Musu-Gillette, L., \& Oudekerk, B. A. (2016). Indicators of school crime and safety: 2015. NCES 2016-079. NCJ 249758. Washington: National Center for Education Statistics. 